\title{
Latent sprawl patterns and the spatial distribution of businesses in a southern European city
}

\author{
Giuseppe Venanzoni ${ }^{1}$, Margherita Carlucci ${ }^{1}$, Luca Salvati ${ }^{2}$, \\ ${ }^{1}$ Department of Social and Economic Sciences, Sapienza University of Rome, Piazzale A. Moro 5, I- \\ 00185 Rome, Italy \\ ${ }^{2}$ Consiglio per la Ricerca e la sperimentazione in Agricoltura, Via della Navicella 2-4, I-00184 Rome \\ (Italy). Phone: +396 70054 13; Fax: +39 670057 11; e-mail: luca.salvati@entecra.it
}

\author{
Correspondence to: \\ Margherita Carlucci \\ Phone: + 39649910654 \\ Fax: + 39649910231 \\ E-mail: margherita.carlucci@uniroma1.it
}




\title{
Latent sprawl patterns and the spatial distribution of businesses in a southern European city
}

\begin{abstract}
Economic restructuring and deindustrialization prodded industrial relocation beyond the physical boundaries of the consolidated built-up area, causing an increase of suburban population and urban sprawl at the regional scale. Southern European cities reflect distinct growth patterns compared to western Europe counterparts: 'urbanization without industrialization' has been often pointed out for several Mediterranean cities. The present study assesses the local-scale impact of the recent economic transition on land-use structure, sprawl patterns and soil consumption in a paradigmatic Mediterranean case (Athens, Greece) with the aim to identify the main economic drivers of sprawl and suburbanization and to provide policy suggestions for a sustainability strategy addressing complex urban models. Clustering of the economic activities identifies a ubiquitous class (commerce) and two groups with distinct localization patterns: i) manufacture, publishing, transport, construction and hotel enterprises in consolidated urban municipalities; ii) mining, energy, telecommunications, real estate/finance, high-tech enterprises concentrated in peri-urban and rural municipalities. Two branches of activities (high-tech and finance/real estate enterprises) characterize the economic structure of 'sprawl' municipalities. This confirms previous hypotheses on the importance of high-tech firms shaping recent sprawl in expanding regions as a more general process of spatial relocation of activities with high returns on capital to peripheral, cheaper land. From the perspective of urban sustainability, it is necessary to rethink a framework that will secure economic development, especially the growth of specialized services, to a land-saving, cohesive spatial structure, through policies promoting mixed compact poles instead of scattered growth in the name of a de-regulated 'polycentric' expansion.
\end{abstract}

Keywords: Urban economics, High-tech enterprises, Suburbanization, Urban gradient, Athens, Mediterranean city. 


\section{INTRODUCTION}

Urban growth and development trends changed radically along the last century and are related to a mix of socioeconomic factors making the joint analysis of urban morphology and economic functions a complex and challenging issue (Kazepov, 2005; Phelps et al., 2006; Torrens, 2008). Urban expansion is shaped by multifaceted factors influenced by the recent development path and the economic base at the country scale, the (changing) socio-spatial structure, political and cultural issues, and territorial (e.g. topographic, environmental) conditions (Couch et al., 2007). In most advanced industrial countries, for the most part of their history, industrialization stimulated urbanization and vice-versa in a circular causation of uneven territorial development (Whitehand and Morton, 2006). Evidence demonstrated that economic restructuring and the transformation of the production base of a given region created industrial relocation beyond the physical boundaries of the consolidated built-up area, causing an increase of suburban population and urban sprawl (Brueckner, 2000). The idea behind is that urban growth is the result of a market equilibrium where competing claims to the land are appropriately balanced (Brueckner and Fansler, 1983 and, even with some caveat about possible market failure, McGrath, 2005). The logical consequence of urban settlements being 'creatures of the market' would be that urban planners should 'aim to improve the functioning of urban settlements, and not become preoccupied with their size' (Gill and Goh, 2010, p.235). On the other hand, urban sprawl has been held responsible for important negative externalities, first of all inefficiency both in energy use and land consumption (Couch et al., 2007) and it has also been found positively associated with lower average labour productivity (Fallah et al., 2011). While suburbanization is stimulated by changes in the sectoral composition of economic activities at the regional scale, more localized sprawl processes, reflected in mixed uses of land and scattered fringe settlements, depend on the localization preferences of specific groups of enterprises, organized in clusters or districts, or more dispersed through the suburban space in search for cheap, accessible land to develop (Richardson and Chang-Hee, 2004; Bruegmann, 2005; Phelps et al., 2006). Even apparently monocentric cities could reveal a more polycentric structure of firms' locations at the micro-level (Ahlfeldt and Wendland, 2013). In particular, firms in sectors as business and financial services, and information and communication technologies often preferred locations in the urban fringe and/or along motorways (Gaschet, 2002). The spatial pattern that resulted is more scattered than polycentric, and is associated with former trends in (peri-)urbanization processes (Riguelle et al. 2007). Moreover, in case of large-scale development projects, foreign direct investments have proved to be important drivers of land use change, with limited, if any, influence of local land users (Seto and Kaufmann, 2003).

This transition created a subtle change in the morphology of several cities shifting towards settlement scattering, land-use mixité and impressive land consumption with uncertain benefits in terms of urban 
competitiveness (Cervero, 2001). In particular, Partridge and Olfert (2011) pinpoint that uncertainity is greater when local communities engage in wasteful economic competition using expensive tax incentives and subsidies to attract favored industries. In this case, they may be forced to reduce services or raise taxes on the rest of the region's residents and firms to offset the tax breaks (or subsidies) they gave to favored firms. In the case of decentralization in the fringe, with suburbs competing with a core city, economic activity is simply rearranged without creating any new wealth.Southern European cities reflect distinct growth patterns compared to affluent, western Europe counterparts; urbanization and urban sprawl phenomenon have experienced a very complex interrelation with industrial restructuring in the Mediterranean region (Wynn, 1984). "Urbanization without industrialization" has been often pointed out for several cities, including Rome, Naples, Athens and, in part, Barcelona and Istanbul (Leontidou, 1990; Catalàn et al., 2008; Yüzer and Yüzer, 2014; Salvati, 2014a, among others). In these cities, diffuse urbanization ran parallel to industrial decline and services decentralization, fuelled by the increase of traditional, labour-intensive small units and the consolidation of a large informal sector with negative implications for urban competitiveness (Leontidou 1996). At the same time, following a long debate on the stereotypical economic models for southern European cities, scholars were progressively abandoning the 'myth' of a unifying Mediterranean framework, moving to more general reflections on urban growth, settlement models, economic structures and socioeconomic development patterns embraced in key-words such as diversification, entropy and fragmentation (Leontidou 1993).

Interestingly, evidence suggest that the informal sector mainly absorbs labourers in the inner cities and popular suburbs (Leontidou, 1990). A widespread informal economy may thus work against sprawling, but not necessarily against suburbanization, which is more related with casual work (Leontidou 1993). With the massive presence of migrants from the Balkans and the Middle East, changes towards a more casual suburban labour market were observed in Athens (Leontidou, 1996), indirectly stimulating dispersed urbanization. The shift in the activities' location pattern and changes in the use of land stimulated an increase in suburban population, alimenting a vicious cycle with land consumption (Burgel, 2004). Unfortunately, urban competitiveness did not seem to benefit significantly from this new spatial organization, with production structures centered on mixed traditional-specialized services (Chorianopoulos et al., 2014).

The spontaneous urban patterns that determine economic polarization and social stratification - apparently so far from northern and western urban models - are rapidly changing in the Mediterranean cities (Vaiou, 1997). However, this transition does not seem to drive them far away from a traditional model of deregulated urban growth, disordered urban tissue, and sometimes scattered economy (Giannakourou, 2005). By abandoning the compact model prevailing up to the 1980 s and consolidated by informal economic growth, the risk to have more scattered cities with stable (or even increasing) population, rising 
unemployment and a modest socioeconomic development is real and may in turn produce an environmentally-unsustainable urban model based on land consumption (Salvati et al., 2013). An inefficient use of land, abandoning compact morphologies and traditional socio-spatial structures, together with modest economic performances due to the persistence of traditional tertiary sectors - further depressed by the current international crisis - reduces the overall sustainability of such urban models. Uncompetitive and sprawled urban models are alimented by ineffective planning at vastly different geographical scales, which is considered a barrier to sustainable development (Chorianopoulos et al., 2010).

Aim of this study is to capture and describe the impact of the economic transition on land-use structure, sprawl patterns and soil consumption in a paradigmatic Mediterranean case, so as to identify (and possibly distinguish) the main economic drivers of sprawl and suburbanization and to provide policy suggestions for a sustainability strategy addressing complex and entropic urban models. With urban fragmentation (Leontidou, 1993), methodologies providing a structured account of hierarchical causality among economic and social factors, such as Alonso's model or the 'urban life cycle' approach, will more likely fail to capture the complexity of processes and aspects of urban contexts leading to suburbanization and sprawl. By contrast, hypothesizing that multifaceted, non-linear aspects shape post-modern urban societies and economies, we developed an exploratory data analysis of the relationship between enterprise localization and land-use regimes with impact on soil sealing profile and the local territorial context. Thus, the main objectives of the present study are (i) to explore the (changing) economic structure of Athens' region in relation to land consumption patterns and efficiency in the use of land, in the light of urban sustainability, (ii) to identify the localization preferences of the main economic activities operating in the area and competing for land as based on territorial factors relevant at both regional and local scale and (iii) to reflect on a more sustainable spatial organization based on competitive economic structures and landsaving morphologies for the Mediterranean cities. Athens' case is interesting for different reasons: first, as an example of the transition of the Mediterranean cities from a compact model to a more scattered configuration; second, as a unique case for urban transformation determined by a mega-event such as the 2004 Olympic games (Zagorianakos, 2004). The novelty of the approach proposed here lies in the exploratory analysis of the urban context with the aim to identify links among economic structure, landuse patterns and settlement morphology in the light of urban sustainability.

\section{Methodology}

\subsection{Study Area}


The region investigated in the present study covers the metropolitan area of Athens, the capital of Greece, and includes a major part of Attica region (Figure 1). The area was partitioned in four prefectures (Athens, Piraeus, East Attica and West Attica) administered by 114 municipalities before the national reform of local administration (the so called 'Kallikratis' law enforced in 2011 which reduced the number of local councils to nearly 60 in the area), with the inner city administered by Athens' municipality. Attica region is characterized by undulated morphology due to the presence of four large mountains that reduces land availability to edification and influences the accessibility of some municipalities. Athens' economy is service-oriented and centered around sectors such as finance, banking, insurance and real estate (Delladetsima, 2006). The entire Attica shows a slow transition towards a service-oriented economy with the tertiary sector accounting for $72 \%$ of the regional value added in 1988 and $87 \%$ in 2007 and the secondary sector declining from $27 \%$ in 1988 to $13 \%$ in 2007. Manufacture and constructions, two important industrial sectors in the region, produced respectively $11 \%$ and $5 \%$ of the regional value added in 1995 decreasing to $8 \%$ and 4\% in 2006 (Table 1). The 2004 Olympic Games had a major impact on the development of the city in terms of investment and infrastructure (Salvati et al., 2013). Despite suburbanization processes driven by the Olympics, the urban area (Athens, Piraeus and the neighbouring municipalities) is still growing, as shown by official population data (Grekousis et al., 2013). The intensity of soil sealing is higher in the centre and lower in the suburbs, indicating the persistence of a mono-centric spatial organization for the entire region (Figure 1).

\subsection{Data and variables}

\subsubsection{Land-use data}

A map developed as part of the Urban Atlas (UA) initiative was used to assess land-use distribution at the metropolitan level in Athens. The UA project is the major initiative dealing with high-resolution land-use monitoring in Europe and represents an information tool for both assessment and policy analysis (European Environment Agency, 2011). The initiative was undertaken by the European Environment Agency (EEA) within the Global Monitoring for Environment and Security framework. UA offers highresolution cartography of 283 European urban areas (more than 100.000 inhabitants as defined by the Urban Audit project for the reference year 2006) assessing 20 land-use classes within four hierarchical levels: (i) artificial surfaces with uses related to non agricultural human activities (i.e. urban areas), (ii) agricultural, semi-natural and wetland uses, (iii) forests and (iv) water bodies (Table 2). Artificial structures are defined as surfaces with dominant human influence but without agricultural use (buildings, roads, all constructions of infrastructure and other artificially sealed or paved areas). Minimum overall 
accuracy for level 1 'Artificial surfaces' class and for the remaining classes was respectively $85 \%$ and $80 \%$ (European Environment Agency, 2011). Data are disseminated by EEA (http://www.eea.europa.eu/dataand-maps/data/urban-atlas). The UA study regions encompass the boundaries of the related 'Large Urban Zones' identified in the framework of the Urban Audit program. Input data sources include Earth Observation (EO) data with $2.5 \mathrm{~m}$ spatial resolution multispectral or pan-sharpened (multispectral merged with panchromatic) data. Multispectral data include near-infrared band together with topographic maps at 1: 50,000 scale. UA maps are scaled 1:10,000 with 0.25 ha Minimum Mapping Unit.

\subsubsection{Soil sealing data}

The spatial distribution of impervious surfaces has been assessed in the present study using the EEA soil sealing map monitoring pavement structures (roads, sidewalks, driveways and parking lots) that are covered by impenetrable materials such as asphalt, concrete, brick, stone and rooftops (European Environment Agency 2006). This raster map incorporates a data set of built-up areas including continuous degree of soil sealing ranging from $0 \%$ to $100 \%$ in 100x100 m spatial resolution with European coverage. Multi-sensor and bi-temporal, ortho-rectified satellite imagery (IMAGE2006) was used to derive soil sealing data covering 38 European countries. The map, freely available in GeoTiff format, refers to 2006 (European Environment Agency 2011). In order to validate the soil sealing EEA map, very high resolution Google Earth imagery was used as supplementary dataset. Reference sealing percentages were obtained using a $10 \times 10 \mathrm{~m}$ grid positioned around the sampling points. Checking classification accuracy was understood as estimating omission error, commission error, and overall accuracy. Classification accuracy of built-up and non built-up areas is higher than $85 \%$ per hectare and both omission and commission errors are below 15\% (European Environment Agency 2011). The composition of sealed land in each Attica's municipality was studied by computing the percent surface area of 22 classes at different imperviousness $(0 \%, 1-5 \%, 6-10 \%, \ldots, 91-95 \%, 96-99 \%, 100 \%)$. Calculations were done by using the 'Tabulate areas' tool provided with ArcGIS software (ESRI Inc., Redwoods, USA) after the overlap between the soil sealing raster map and the shapefile depicting municipal boundaries. The 'Tabulate areas' procedure computes selected statistics including count of the raster values recorded on each elementary $100 \times 100 \mathrm{~m}$ pixel belonging to the examined municipalities.

\subsubsection{Territorial indicators}

Eleven territorial indicators have been derived at the municipal scale from the aforementioned maps and from official statistics. Indicators have been selected with the aim at providing a summary description of 
basic territorial characteristics in the investigated area (Salvati, 2014a). Indicators include three soil sealing variables: (i) sealing intensity (\%), providing information on urban form (compact $v s$ dispersed) and land consumption patterns (Int), (ii) per-capita sealed land $\left(\mathrm{m}^{2}\right)$, evaluating the efficiency in the use of land destined to urban development (Pro) and (iii) diversity in the composition of sealed land (Eve) as a proxy of urban primacy. Pro was derived from the total sealed surface area divided by the resident population in 2011, Int was an average sealing intensity index weighted by the surface land of each imperviousness class and, finally, Eve was calculated as the Pielou's evenness index derived from the Shannon index of diversity applied to the composition of sealed land in each municipality (Eve $=\mathrm{H} / \mathrm{H}_{\max }$ where $H_{\max }$ is the logarithm of the number of considered classes: $n=22$ and ranges between 0 (low diversity) and 1 (high diversity)). Four indicators (population density in 2001: Den, annual population growth rate (\%) in 2001-2011: Var, linear distance $(\mathrm{km})$ from Athens' centre: Dis, and municipal surface area $\left(\mathrm{km}^{2}\right)$ : Sup) have been derived from the National Census of Population and Household carried out by the Greek Statistical Authority (ELSTAT) in 2001 and 2011 and from elaborations on topographic maps (Salvati et al. 2013). Four additional indicators have been derived for each municipality from the UA map: the percent area of residential settlements, the ratio of compact settlement to dispersed settlement area, the total urban area and the ratio of agricultural to forest area.

\subsubsection{Economic structure}

A total of 14 indicators have been used to describe the economic structure of Attica's municipalities using data extracted from the national Business Register held by Ministry of Finance and disseminated for statistical purposes by ELSTAT. Eleven basic economic activity classes referring to 2005 for industry (4 classes) and services (7 classes) have been considered here including both traditional activities (such as constructions and commerce) and high-value added specializations such as real estate/finance/banking, tourism and telecommunications, among others. Three economic sectors have been considered (agriculture, industry and services) producing three additional indicators. All indicators have been calculated as the percent ratio of local units belonging to a given activity class to the total number of units registered in each studied municipality.

\subsection{Statistical Analysis}

The spatial distribution of each indicator was explored through maps based on official municipal boundaries produced by ELSTAT in 2011. A hierarchical clustering (using Euclidean distances and Ward's agglomeration rule) was developed separately on the variables belonging to the four themes (land- 
use, soil sealing, territory [plus 3 basic economic activities: agriculture, industry, services], economic structure) with the objective to study the similarity in the spatial distribution of the studied indicators. A correlation analysis using Spearman non-parametric rank tests was carried out to compare pair-wise the spatial distribution of the 14 economic indicators with (i) 20 land-use indicators, (ii) 22 soil sealing indicators and (iii) 11 territorial indicators, testing at $p<0.05$ after Bonferroni's correction for multiple comparisons. A Principal Components Analysis (PCA) was carried out on the matrix constituted by the 67 indicators (see Table 2) for each municipality of the study area with the aim to identify the main factors characterizing the economic profile at the local scale in Attica and the latent relationships between the economic structure and land-use/soil sealing patterns. Components with eigenvalue $>3$ were extracted plotting component loadings and scores separately. Finally, the percent rate of change in the number of registered businesses for each municipality of the study area was calculated for the period 2002-2008 and mapped. This variable was also correlated with land-use, soil sealing, territory and economic indicators using pair-wise non parametric Spearman rank coefficients testing at $p<0.05$.

\section{RESULTS}

\subsection{Exploring the spatial structure of Athens' metropolitan area}

The spatial distribution of selected variables in Attica was mapped in Figure 1. Maps indicate a typical mono-centric spatial pattern with impervious land corresponding to Athens' consolidated urban area and population growth concentrated along Athens' fringe. Economic activities showed a different localization pattern with construction enterprises (Con) operating in peri-urban municipalities, publishing companies (Pub) concentrated in urban municipalities and hotels (Hot) localized along the coast and in mountain tourism places. Real estate and finance activities (Fin) showed a suburban localization pattern concentrating in northern and southern Athens' fringe. High-tech firms (Hig) concentrated in the northern fringe of Athens (corresponding to the municipalities hosting the majority of 2004 Olympics infrastructures). Finally, service enterprises showed a mixed spatial pattern reaching the highest density in fringe municipalities of Athens' conurbation.

Hierarchical clustering (Figure 2) illustrates the spatial structure of Athens' metropolitan area identifying similarities in land-use and soil sealing patterns as well as in the spatial distribution of economic and territorial indicators. Hierarchical clustering discriminates between urban and rural municipalities according to the prevailing land-use regime (urban $v s$ agriculture/forest) and settlement form (compact $v s$ dispersed settlements). Urban municipalities are characterized by mixed continuous/compact and mediumdensity residential settlements together with industrial areas, urban parks and forest land. Rural 
municipalities are better identified by low-density discontinuous settlements, isolated buildings, construction sites, infrastructure and mixed agricultural-natural areas. Results of hierarchical clustering on sealing indicators corroborates these findings identifying an imperviousness gradient centered on Athens' area. Hierarchical clustering on territorial indicators' identifies the variables mostly associated to the urban-rural gradient in Attica: one group is formed by five variables indicating urban centrality, residential land-use, high impervious rate and the associated economic activities. The second group includes the remaining nine variables possibly describing mixed land-uses centered on low-density settlements, infrastructures and agricultural areas with high per-capita built-up area. Finally, economic activities' clustering summarizes the economic structure of Athens' region identifying a ubiquitous class (commerce) and two groups of activities with different localization patterns (manufacture, publishing, transport, construction and hotel enterprises concentrated in Athens' urban area and mining, energy, telecommunications, real estate/finance, high-tech and agricultural enterprises mainly located in rapidly expanding peri-urban and rural municipalities).

\subsection{Exploring the spatial relationship between economic activities and territorial indicators}

Results of the non-parametric correlation analysis between economic activities and land-use, soil sealing and territorial indicators are reported in Tables 3-5. Taken together, Spearman coefficients reveal a specific localization profile for almost all activities. Mining and energy enterprises localized especially on marginal, fringe land without current use (1340) or under construction (1330). Manufacture enterprises settled preferentially on compact (1110), high density (Com/Dis) and non-residential areas (1210) with sealing rate $>75 \%$ and railway accessibility (1223). Construction enterprises concentrated in rural municipalities with intense population growth (Var), large availability of agricultural land (2000), isolated structures (1130), higher per-capita built-up area (Pro) and larger municipal surface area (Sup). Publishing companies showed a preference for dense (Den) and compact $(1110,1121)$ urban areas (Int, \%Urb, Eve, 1210) with high accessibility (1222), sealing rate between $36 \%$ and $99 \%$ and amenities (green areas and sport fields: 1410, 1420). As expected, hotels localized preferentially in non-urban, natural (0\% impervious) land (2000, 3000) with isolated structures (1130) along the coasts (5000) and in remote, mountain areas far from Athens (Dis).

Real estate and finance enterprises concentrated in medium-low density $(1122,1123,1124)$ municipalities with dynamic population (Var) and free land to develop (sealing rate between $1 \%$ and $30 \%$ ) surrounding Athens. High-tech firms settled preferentially in medium $(1121,1122)$ density, urban (Urb\%, Den, Dis, Eve) municipalities with access to the main road network (1222), sealing rate between $16 \%$ and $75 \%$ and amenities $(1410,1420)$. Commercial enterprises concentrate in municipalities with compact (1110) and 
dense (Com/Dis) settlements (sealing rate $>75 \%)$, dedicated spaces (1210) and accessibility to railway network (1223). As expected, transport enterprises concentrated in coastal areas (5000) with high sealing rate $(>95 \%)$ and compact settlements (Com/Dis) due to the presence of ports, airports and other infrastructures. Telecommunication firms are characterized by urban localization (Urb\%, Eve) with dense (Den) and compact settlements (1110, 1121, Com/Dis), accessibility to the road network (1222) and amenities (green areas, sport fields: 1410, 1420).

As expected, enterprises working in the primary sector are concentrated in remote (Dis), rural municipalities with predominance of agricultural (2000) non-sealed land (0\%) or in peri-urban municipalities with high surface area (Sup), low-density settlements $(1123,1124,1130)$ and high percapita built-up area (Pro). Enterprises working in the secondary sector showed a localization similar to the enterprises operating in the primary sector, being concentrated in municipalities with high per-capita builtup area (Pro), isolated structures (1130) and higher proportion of agricultural areas (2000). Finally, enterprises operating in the tertiary sector tended to localize in urban (Urb\%, Eve, Den) municipalities with medium-density settlements (1122), high accessibility (1222), sealing rate between $16 \%$ and $60 \%$ and amenities $(1410,1420)$.

\subsection{Principal Component Analysis}

The spatial distribution of the selected land-use, sealing, territorial and economic indicators has been studied through a Principal Component Analysis investigating specific location patterns and latent relationships between the use of land and the localization of enterprises in mainland Attica. The PCA extracted five components with eigenvalue $>3$ explaining more than $60 \%$ of the total variance (Figure 3 ). However, variables' loadings $>10.5 \mid$ were found only for components 1 and 2 cumulating $43 \%$ of the total variance. Component 1 extracted $26 \%$ of the total variance and represents a typical urban-rural gradient with positive loadings attributed to compact and dense settlements $(1110,1121,1222)$ and negative loadings attributed to isolated buildings (1130), agricultural areas (2000) and forest land (3000). The component identified a soil sealing gradient opposing rural municipalities with non-sealed land $(0 \%)$ to urban municipalities with sealing rate $>35 \%$. This spatial pattern is confirmed by territorial indicators with positive loadings attributed to population density (Den), percentage of urban areas (Urb\%), sealing intensity (Int) and diversification (Eve) and negative loadings attributed to dispersed settlements (Dis). Among economic activities, component 1 highlights the polarization in activities localizing in central places (such as publishing enterprises) and those localized in more remote places (such as hotels). Component 2 extracted $18 \%$ of the total variance and identifies a gradient from the inner city with compact and dense settlements (1110, negative loadings) to peri-urban areas with low-density settlements 
(1122, 1123, 1124, positive loadings). The soil sealing profile is in accordance with these findings, with negative loadings attributed to sealing classes $>80 \%$ and positive loadings attributed to classes with sealing rate between $1 \%$ and $40 \%$. The economic activities mostly associated to this gradient are manufacturing and commerce (negative loadings) as well as real estate/finance and high-tech enterprises (positive loadings). Component scores clearly identified three classes of municipalities in Attica (Figure 4): municipalities with economic functions occupying central places (Man, Com, Pub) primarily in the consolidated urban area of Athens, rural municipalities with economic functions occupying more remote places (hotels, agriculture) and a group including urban and rural municipalities with mixed economic functions and peri-urban localization preferences.

\subsection{Changes over time in registered business density and correlation with territorial indicators}

The spatial distribution of the percent change rate of registered businesses in mainland Attica was mapped in Figure 5. The highest rate of growth (> 5\% and, in some cases, $>10 \%$ ) was observed in peri-urban municipalities, especially in Messoghia district east of Athens and in the northern district of Oropos. The consolidated Athens' area totalized a growth rate $<5 \%$ with some municipalities (both central and peripheral) showing a negative rate of growth. Registered businesses increased especially in peripheral (Dis) municipalities with dispersed settlements $(1122,1123,1124,1130)$ and agricultural areas (2000) with sealing rate $<15 \%$, high per-capita built-up area (Pro) and high population growth rate (Var). By contrast, registered businesses declined in dense (Den, Int) urban (Urb\%) municipalities with compact settlements $(1110, \mathrm{Com} / \mathrm{Dis})$ with sealing rate $>60 \%$. The density of registered businesses was not correlated to any economic activity operating at the local scale.

\section{DISCUSSION AND CONCLUSION}

This study focused on a Mediterranean city showing intense and peculiar suburbanization and sprawl processes observed respectively on the regional and the local scale since decades. Owing to a complex set of drivers, suburbanization and sprawl were conditioned by multiple economic causes (population relocation to the suburbs, change in the industrial structure, decline of manufacturing, growth of services with a high return on capital, large volatility of the construction industry), together with the development of 2004 Olympics infrastructures involving the peri-urban area of Athens (Beriatos and Gospodini, 2004). The assessment of the regional economic structure vis à vis land-use patterns and their impact on land-use efficiency (e.g. soil sealing rate, per-capita built-up area) indicates that the location preferences of the economic activities in Attica reflect specific territorial factors at both local and regional scale. The 
economic factors contributing to suburbanization and referring to the expansion of residential settlements and the expulsion of production functions (e.g. construction industry) from the central city, influence the spatial structure of the metropolitan area at the regional scale by producing a typical urban-rural gradient well illustrated by the multivariate analysis (component 1).

Industrial sprawl in Attica is more finely traced on a local scale and exerted the main impact on Athens' fringe at intermediate distances from the consolidated city rather than in more remote areas. This phenomenon is spatially arranged along an urban gradient based on the ratio of compact to dispersed settlements, as shown by the multivariate analysis (component 2). Distinct economic activity location and soil sealing profiles have been identified along the 'suburbanization' and 'sprawl' axes, with different impact on land-use efficiency. Interestingly, two branches of activities (high-tech and finance/real estate enterprises) predominated in 'sprawl' municipalities. This confirms previous hypotheses on the importance of high-tech firms shaping recent sprawl in expanding regions as a more general process of spatial relocation of activities with high returns on capital to peripheral, cheaper land (Heim, 2001; Felsenstein, 2002; Heubeck, 2009). In the long run, however, urban sprawl will expand in rural areas with lower population density, being influenced by possibly different economic agents. The highest per-capita builtup area observed in remote municipalities may thus represent an early-warning proxy for this process. Remote and marginal areas are characterized by a sealing profile dominated by the lowest imperviousness classes $(1 \%-20 \%)$ together with a mixed economic structure centered on agriculture but rapidly changing towards construction and tourism.

The analysis also reveals a strong path-dependency on the consolidated economic structure which was for a long term based on the dichotomy between manufacturing and trade (urban areas) and economic activities that favor scattered and peripheral localization (Hot, Con, Agr) in rural areas. In the case of Athens, the spatial structure of economic activities is molded by the consolidated localization of specific functions (e.g. manufacturing industry, publishing firms), concentrated in central places with compact and dense settlements and by the presence of port infrastructures of national importance. The layering of different stages of urban development with conflicting morphological outcomes and reflecting the distinct location for industrial and service activities, has led to economic polarization in turn contributing to determine a strong social segregation along both axes, at regional (urban-rural) and local (compactdispersed) scale (Maloutas, 2007; Arapoglou and Sayas, 2009; Polyzos et al., 2013).

As already argued elsewhere (Leontidou 1990, 1993, 1996), our results indicate how Athens' spatial structure - along with other cities of Mediterranean Europe - cannot be adequately understood through traditional analysis frameworks, including the 'life cycle' hypothesis and Alonso model or other Anglocentric approaches to urban development (Leontidou, 1996). Our study proposes an alternative framework to examine and interpret urban morphology vs economic functions as based on exploratory data analysis 
of economic, social and environmental indicators at the municipal scale (Heim, 2001; Grekousis et al., 2013; Salvati et al., 2013; Salvati, 2014b). Couch et al. (2007) claims for an integrated approach suitable to capture the latent relationships between sprawl patterns and processes reflected in morphology characteristics and distinctive socioeconomic traits. Our approach tries to address this claim by offering the opportunity to investigate latent relationships among economic structure, land-use patterns and settlement morphology in the light of urban sustainability.

As in other northern Mediterranean countries, Greece developed a settlement system during the whole 19th century that remained scattered in small towns and villages lacking spatial poles of economic activity (Leontidou, 1990). The drastic urbanization of the first half of the 20th century was concentrated in the two urban nodes of the region (Athens and Piraeus) while suburbanization and sprawl became the major issues (if not the dominant ones) in urban restructuring processes and public policy responses after World War II (Costa et al., 1991). Changes in the use of land in post-war decades followed de-industrialization and the consolidation of traditional services representing Athens as a mixed city in both morphological and functional terms (Delladetsima, 2006). The informal economy - dominant on the urban scene at least up to the late 1980s - combined with the lack of planning and coordination, has been evident in a patchwork of activities (Gospodini, 2009). Only a few nuclei of business land were planned and developed, bringing residence, commerce, services and industries into close proximity (Kourliouros, 1997). Industrial decline was moderate in absolute terms, but sometimes important at the local scale, especially in Piraeus district (Leontidou, 1990), and was counterbalanced by a spatially-asymmetric increase of traditional services in central areas and, more recently, innovative services on fringe land (Beriatos and Gospodini, 2004). Couch et al. (2007) identified distinct expansion modes in Athens, only partly in common with what observed in western Europe city regions and with specific relation to industrial development and economic restructuring: (i) ribbon sprawl, (ii) leapfrogging sprawl and (iii) dispersed expansion driven by large infrastructures. In all these cases, changes in location preferences of activities acted as an important factor shaping - at the same time - sprawl patterns and processes. More generally, changes in income distribution, job market structure and land prices, together with the simultaneous increase of investments - especially foreign investments - on land, are considered key drivers of suburbanization in the area (Salvati, 2014b).

Despite some important state interventions aimed at re-localizing manufacture in marginal areas outside the consolidated city (Kourliouros, 1997), land allocation has been especially de-regulated and few business land had been provided with facilities or organized in the form of industrial zones (Delladetsima, 2006). In order to benefit from the agglomeration economies of the central city - without losing benefits granted by new legislation for decentralization - many industries settled on the boundaries of unassisted 
zones along the major road axes (Leontidou, 1996) producing a typical landscape of metropolitan peripheries with poor landscape quality and declining economic value (Salvati et al., 2013).

The institutional milieu for metropolitan development has always been polarized as central/local government, without any important middle tiers (Wassenhoven, 2000). The former suffers from overstaffing and bureaucratic inertia, while the latter is underfunded and institutionally incapable of implementing plans (Costa et al., 1991). As a general rule, local authorities in Greece have a very limited competence in planning and funding urban development and many interventions with a spatial impact remain uncoordinated leaving free hand to ex-post 'legalization' of developed land (Polyzos and Minetos, 2013), including small and large industrial sites (Kourliouros, 1997). Administrative and bureaucratic inertia, multi-authority interference, non-devolution of government, deregulated planning and clientelist politics, together with pressures by landowners were - and, in some way, are - major barriers to an effective (and land-saving) planning of peri-urban land destined to service and industrial activities in Greece and, more in general, in the Mediterranean basin (Giannakourou, 2005). In this framework, the well-known impact of specific economic sectors - such as high-tech enterprises or real estate/financial companies ( $\mathrm{Ye}$ and $\mathrm{Wu}, 2014$ ) - on local sprawl add to the factors mentioned above producing unsustainable development on the fringe, with high per-capita land consumption, soil sealing and a low compact to dispersed settlement ratio being the most significant signals of ineffective planning (Salvati et al., 2013).

In the last decade, however, increasing land controls after EU integration, in combination with the preparation works for the 2004 Olympics, have created a set of development models comparable to those of other metropolitan cities in Europe and the Unites States, driven by urban competition and place marketing (De Maesschalck, 2010; Cassier and Kesteloot, 2012; Paulsen, 2014). Organized developers and public-private partnerships have penetrated specific areas especially in Messoghia district, with the contribution of infrastructures such as the new underground service and the suburban railway network connecting fringe land to the central city. These major works encourage land speculation by organized partnerships in localities where petty speculation and fragmentation used to thrive (Turner, 2007). The role of leading actors in Athens' sprawl such as the state, certain public-private partnerships, cooperatives and the private sector was emphasized by various scholars (Beriatos and Gospodini, 2004; Couch et al. 2007; Gospodini, 2009). The strive for visibility by the attraction of international events, grand speculation, urban competition and place marketing offered additional motivations for urban sprawl through the development of new infrastructures and commercial settlements (Delladetsima, 2006) in turn stimulating service delocalization and a further wave of small-scale industry scattered suburbanization (Chorianopoulos et al., 2010). 
From the perspective of urban sustainability, it is necessary to rethink a framework that will secure economic development, particularly the growth of specialized services, to a land-saving, cohesive urban structure through policies promoting mixed economic-residential compact poles around the consolidated urban area instead of scattered growth in the name of a de-regulated 'polycentric' expansion (Suarez-Villa and Walrod, 1997; Prud'homme and Lee, 1999; Maoh and Kanaroglou, 2007). This can be done through a more tight control in the price of the land, that has great influence in the processes of industrial relocation. Moreover, the recovery of the inner compact areas should not be linked exclusively to residential purposes, but it can easily rebuild a settlement fabric suitable for hosting high-tech enterprises, at least in the most accessible places (Schlichtman, 2009). Interestingly, as it was observed in Messoghia district, the chaotic economic functions derived from different forms of sprawl, including ribbon, leapfrog and infrastructure sprawl, do not seem to promote, in the long run, a model of spontaneous industrial settlements (Souliotis, 2013). On the contrary, industries tend to settle in areas previously planned and in part already built-up, indirectly promoting settlement densification, economic de-polarization and social re-balancing (Chorianopoulos et al., 2014). Such a (spontaneous) 'self-contained expansion' model appears in nисе a bottom-up response to both local and regional processes (planning deregulation, land prices, volatility in the market demand, globalization) reflecting the crisis of a socially-imbalanced and environmentally-unsustainable 'smart' Mediterranean city model (Herrschel, 2013).

\section{REFERENCES}

Ahlfeldt G.M., Wendland N. (2013) How polycentric is a monocentric city? Centers, spillovers and hysteresis. Journal of Economic Geography 13, 53-83.

Arapoglou, V. P. and Sayas, J. (2009). New Facets of Urban Segregation in Southern Europe: Gender, Migration and Social Class Change in Athens. European Urban and Regional Studies 16(4), 345-62.

Beriatos, E. and Gospodini, A. (2004). Glocalising urban landscapes: Athens and the 2004 Olympics. Cities 21, 187-202.

Brueckner J.K. (2000). Urban sprawl; diagnosis and remedies. International Regional Science Review 23(2), 160-171

Brueckner J.K. and Fansler D.A. (1983) The Economics of Urban Sprawl: Theory and Evidence on the Spatial Sizes of Cities. The Review of Economics and Statistics, 65(3), 479-482.

Bruegmann, R. (2005). Sprawl: a compact history. University of Chicago Press, Chicago, 301 pp.

Burgel, G. (2004). Athènes, de la balkanisation à la mondialisation. Méditerranée 103(3-4), 59-63.

Cassiers, T. and Kesteloot, C.. (2012). Socio-spatial Inequalities and Social Cohesion in European Cities. Urban Studies 49(9), 1909-24. 
Catalàn, B., Sauri, D., Serra, P. (2008). Urban sprawl in the Mediterranean? Patterns of growth and change in the Barcelona Metropolitan Region 1993-2000. Landscape and Urban Planning 85, 174-184.

Cervero R, (2001) Efficient urbanization: Economic performance and the shape of the metropolis. Urban Studies 38(10), 1651-1671.

Chorianopoulos I., Tsilimigkas G., Koukoulas S., Balatsos T. (2014). The shift to competitiveness and a new phase of sprawl in the Mediterranean city: Enterprises guiding growth in Messoghia - Athens. Cities 39, 133-143.

Chorianopoulos, I., Pagonis, T., Koukoulas, S., Drymoniti, S. (2010). Planning, competitiveness and sprawl in the Mediterranean city: The case of Athens. Cities, 27(4), 249-259.

Costa, F., Noble, A.G., Pendleton, G. (1991). Evolving planning systems in Madrid, Rome, and Athens. Geojournal 24, 293-303.

Couch, C., Leontidou, L. Petschel-Held, G., (2007). Urban Sprawl in Europe - Landscapes, Land-Use Change \& Policy. Oxford: Blackwell Publishing.

De Maesschalck F. (2010). The politicisation of suburbanisation in Belgium: towards an urban-suburban divide. Urban Studies 48(4), 699-717.

Delladetsima P. (2006). The emerging property development pattern in Greece and its impact on spatial development, European Urban and Regional Studies, vol. 13(3), pp. 245-278.

European Environment Agency (2006). Urban sprawl in Europe - The ignored challenge. Copenhagen: EEA Report no. 10.

European Environment Agency, (2011). Mapping guide for a European urban atlas. Copenhagen: available at http://www.eea.europa.eu/data-and-maps/data/urban-atlas (last access December 2014)

Fallah B.N., Partridge M.D., Olfert M.R. (2011) Urban sprawl and productivity: Evidence from US metropolitan areas, Papers in Regional Science, 90(3), 451-473.

Felsenstein D. (2002). Do high technology agglomerations encourage urban sprawl? Annals of Regional Science (2002) 36, 663-682.

Gaschet F. (2002) The new intra-urban dynamics: suburbanization and functional specialization in French cities. Papers in Regional Science 81, 63-81.

Giannakourou, G. (2005). Transforming spatial planning policy in the Mediterranean countries. European Planning Studies 13(2), 319-331.

Gill I.S. and Goh C.C. (2010). Scale economies and cities. World Bank Research Observer 25(2), 235262.

Gospodini A. (2009). Post-industrial trajectories of Mediterranean European cities: the case of postOlympic Athens. Urban Studies 46(5-6), 1157-1186. 
Grekousis, G., Manetos, P., Photis, Y. N. (2013). Modeling urban evolution using neural networks, fuzzy logic and GIS: The case of the Athens metropolitan area. Cities, 30, 193-203.

Heim C.E. (2001). Leapfrogging, Urban Sprawl, and Growth Management: Phoenix, 1950-2000. American Journal of Economics and Sociology, 60(1), 245-283.

Herrschel T. (2013). Competitiveness and sustainability: can 'Smart City Regionalism' square the circle? Urban Studies 50(11), 2332-2348.

Heubeck S. (2009). Competitive sprawl. Economic Theory 39, 443-460.

Kazepov, Y. (2005). Cities of Europe: changing contexts, local arrangements, and the challenge to urban Cohesion. Oxford: Blackwell.

Kourliouros, E. (1997). Planning industrial location in Greater Athens: the interaction between deindustrialization and anti-industrialism during the 1980s. European Planning Studies, vol. 5(4), pp. 435460.

Leontidou, L. (1990). The Mediterranean city in transition. Cambridge: Cambridge University Press.

Leontidou L. (1993). Postmodernism and the city: Mediterranean versions. Urban Studies 30(6), 949-965.

Leontidou, L. (1996). Alternatives to modernism in (Southern) urban theory: exploring in-between spaces, International Journal of Urban and Regional Research, vol. 20(2), pp. 180-197.

Maloutas, T. (2007). 'Socio-Economic classification models and contextual difference: the 'European Socio-economic Classes' (ESeC) from a South European angle. South European Society and Politics 12:4, $443-60$.

Maoh, H., Kanaroglou, P. (2007). Geographic clustering of firms and urban form: A multivariate analysis. Journal of Geographical Systems, 9, 29-52.

McGrath D.T. (2005) More evidence on the spatial scale of cities. Journal of Urban Economics 58(1), 110.

Partridge M.D. Olfert M.R. (2011) The winners' choice: sustainable economic strategies for successful 21st-century regions. Applied Economic Perspectives and Policy 33(2), 143-178.

Paulsen K. (2014). Geography, policy or market? New evidence on the measurement and causes of sprawl (and infill) in US metropolitan regions. Urban Studies 51(12), 2629-2645

Phelps N.A., Parsons N., Ballas D., Dowling A. (2006). Post-suburban Europe: planning and politics at the margins of Europe's capital cities. Basingstoke, Palgrave Macmillan.

Polyzos, S., \& Minetos, D. (2013). Informal housing in Greece: A multinomial logistic regression analysis at the regional level. European Spatial Research and Policy, 20(2), 57-85.

Polyzos, S., Minetos, D. \& Niavis, S. (2013). Driving factors and empirical analysis of urban sprawl in Greece. Theoretical and Empirical Researches in Urban Management, 8, 5-28. 
Prud'homme, R., and Lee, G. (1999). Sprawl, speed and the efficiency of cities. Urban Studies, 36, 18491858.

Richardson H. and Chang-Hee C., (2004). Urban sprawl in Western Europe and the United States. London: Ashgate.

Riguelle F., Thomas I. and Verhetsel A. (2007). Measuring urban polycentrism: a European case study and its implications Journal of Economic Geography 7(2), 193-215.

Salvati L. (2014a). Towards a Polycentric Region? The Socioeconomic Trajectory of Rome, an 'ethernal' Mediterranean City. TESG - Journal of Economic and Social Geography 105(3), 268-284.

Salvati L. (2014b). Neither Ordinary nor Global: A Reflection on the 'Extra-ordinary' Expansion of Athens. Urban, Planning and Transport Research. DOI: 10.1080/21650020.2014.898571.

Salvati, L., Sateriano, A. and Bajocco, S. (2013). To grow or to sprawl? Land cover relationships in a Mediterranean city region and implications for land use management. Cities 30, 113-121.

Schlichtman J.J. (2009). The Niche City Idea: How a Declining Manufacturing Center Exploited the Opportunities of Globalization. International Journal of Urban and Regional Research 33(1), 105-125.

Seto K.C. and Kaufmann R.K. (2003) Modeling the Drivers of Urban Land Use Change in the Pearl River Delta, China: Integrating Remote Sensing with Socioeconomic Data. Land Economics 79(1), 106-121.

Souliotis N. (2013). Cultural economy, sovereign debt crisis and the importance of local contexts: The case of Athens. Cities 33, 61-68.

Suarez-Villa L, Walrod W (1997) Operational strategy, R\&D and intra-metropolitan clustering in a polycentric structure: The advanced electronics industries of the Los Angeles Basin. Urban Studies 34(9), 1343-1380.

Torrens P.M. (2008). A Toolkit for Measuring Sprawl. Appl. Spatial Analysis 1, 5-36.

Turner M.A. (2007). A simple theory of smart growth and sprawl. Journal of Urban Economics 61, 21-44. Vaiou, D. (1997). Facets of spatial development and planning in Greece, European Planning Studies, vol. 5(4), pp. 431-433.

Whitehand J.W.R., Morton N.J. (2006). The Fringe-belt Phenomenon and Socioeconomic Change. Urban Studies 43(11), 2047-2066.

Wynn, M. (1984). Planning and urban growth in Southern Europe. Mansell, London \& New York.

Ye L., Wu A.M. (2014) Urbanization, land development, and land financing: evidence from Chinese cities, Journal of Urban Affairs,

Yüzer M.A., Yüzer A.S. (2014). Changes in land-use preferences of small-, medium- and large-scale industries located in metropolitan areas (case study in Istanbul). European Planning Studies, 22(6), 11271142 
Wassenhoven L. (2000). The EU Compendium of Spatial Planning Systems and Policies: Greece. European Commission Regional Development Studies, Luxembourg.

Zagorianakos, E. (2004). Athens 2004 Olympic Games' Transportation Plan: a missed opportunity for Strategic Environmental Assessment (SEA) integration, Journal of Transport Geography 12, 115-125. 